\title{
Structural Diversity and Biological Potential of Alkaloids from the Genus Hippeastrum, Amaryllidaceae: an Update
}

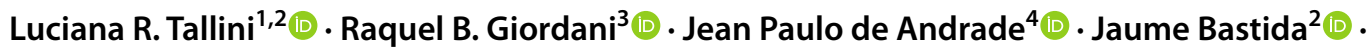 \\ José Angelo S. Zuanazzi ${ }^{1}$ (D)
}

Received: 7 September 2021 / Accepted: 27 October 2021 / Published online: 14 December 2021

(c) The Author(s) under exclusive licence to Sociedade Brasileira de Farmacognosia 2021

\begin{abstract}
The subfamily Amaryllidoideae, Amaryllidaceae, presents an exclusive group of structures known as Amaryllidaceae alkaloids, which have a broad spectrum of biological activities. These plants are classified into 59 genera, including Hippeastrum Herb., which comprises approximately 60 species distributed mainly in South America, being widely used as ornamental plants due to the beauty of its flowers. This review presents an update about the alkaloid profiling of Hippeastrum extracts published between 2012 and 2021, as well as an approach to the biological potential of these compounds.
\end{abstract}

Keywords Alzheimer's disease $\cdot$ Anti-inflammatory $\cdot$ Antitumoral $\cdot$ Antiparasitic $\cdot$ Cytotoxic $\cdot$ Isoquinoline alkaloids

\section{Introduction}

The prospection of medicinal plants has always been important for the human health and the need for medicines from natural origin is as extensive as it is thought to be a deep evolutionary behavior (Hardy 2021). Recently, the COVID19 pandemic reinforced how essential it is to have molecules available to cure or, at least, mitigate illnesses (Chinsembu 2020; Komolafe et al. 2021). In this context, the discovery and isolation of additional novel compounds, linked to their biological activities, is a remarkable contribution to the

This article is part of a Special Issue to celebrate the 35 th anniversary of the Brazilian Journal of Pharmacognosy

José Angelo S. Zuanazzi

zuanazzi@ farmacia.ufrgs.br

1 Programa de Pós-graduação em Ciências Farmacêuticas, Faculdade de Farmácia, Universidade Federal do Rio Grande do Sul, Porto Alegre, RS 90610-000, Brazil

2 Grup de Productes Naturals, Departament de Biologia, Sanitat i Medi Ambient, Facultat de Farmàcia i Ciències de l'Alimentació, Universitat de Barcelona, 08028 Barcelona, Spain

3 Departamento de Farmácia, Universidade Federal do Rio Grande do Norte, Natal, RN 59012-570, Brazil

4 Instituto de Investigación Interdisciplinaria, Vicerrectoría Académica, Universidad de Talca, Campus Talca, 3460000 Talca, Chile human health. Among the molecules synthesized by plants, the alkaloids have provided significant biological benefits (Cordell et al. 2001).

The Amaryllidoideae, an Amaryllidaceae subfamily, is one of the 20 most relevant alkaloid-containing plants group, comprising more than 800 perennial bulbous species classified into 59 genera (Spies et al. 2011; Berkov et al. 2020). These plants synthesize a consistent class of isoquinolinelike alkaloids, known as Amaryllidaceae alkaloid (AA), that have shown remarkable pharmacological activities such as antiparasitic, antiproliferative, antifungal, cytotoxic, psychopharmacologic, and acetylcholinesterase-inhibitory, among others (Bastida et al. 2006).

The AA are derived from the aromatic amino acids phenylalanine and tyrosine and are synthesized within the norbelladine pathway (Battersby et al., 1961; Singh and Desgagné-Penix 2014). Norbelladine is methylated to form 4'-O-methylnorbelladine (1), which serves as a key intermediate for multiples biosynthetic pathways, and the phenolic oxidative coupling of this structure results in the formation of different groups of AA (Scheme 1) (Barton and Cohen 1956, Bastida et al. 2006; Kilgore and Kutchan, 2015; Cahlíková et al. 2021). In a recent review, the AA were classified into 42 skeleton types, including protoalkaloids (found in many Amaryllidaceae plants), Sceletium, and miscellaneous alkaloid characteristics of other plant families (Berkov et al. 2020). More than 600 different structures of AA are available in this plant family (Berkov et al. 2020). 
<smiles>Cn1ccc2cc(CCO)cc(-c3cc4c(cc3CO)OCO4)c21</smiles>

Galanthindole type 5<smiles>CNc1ccccc1-c1cc2c(cc1CO)OCO2</smiles>

Ismine type 11<smiles>COc1cc2c(cc1OC)[C@H]1C3NCCC3=CC[C@@H]1OC2=O</smiles>

Homolycorine type

$$
8
$$<smiles>[3H][3H]</smiles><smiles>COc1cc2c(cc1OC)[C@@]1(OC2=O)[C@@H](O)[C@H](OC)[C@H]2OC23CCN(C)[C@H]31</smiles>

Galasine type<smiles></smiles>

Lycorine type 7

1 †ortho-para'

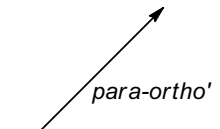<smiles>COc1ccc(CNCCc2ccc(O)cc2)cc1O</smiles>

Norbelladine type 1 para-para'

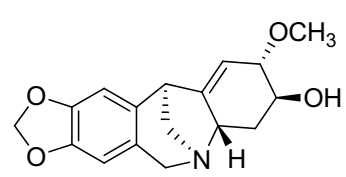

Montanine type

3

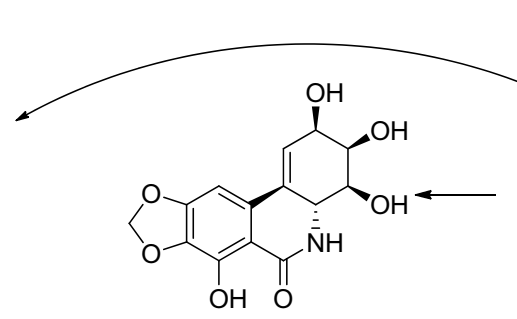

Narciclasine type 12

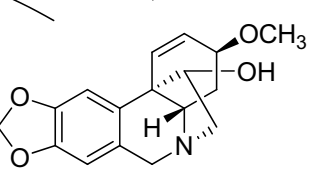

Haemanthamine type 9<smiles>COc1ccc2c3c1O[C@H]1C[C@@H](O)C=C[C@@]31CCN2C</smiles>

Galanthamine type 2<smiles>COC1C=C[C@]23c4cc5c(cc4C(O)O[C@H]2CN(C)C3C1)OCO5</smiles>

Pretazettine type 10

Scheme 1 Phenolic oxidative coupling of the Amaryllidaceae alkaloids skeleton-type found in Hippeastrum extracts between 2012 and 2021 , and their representative alkaloids. Adapted from Berkov et al. (2020)

Galanthamine (2) is the most renowned AA due to its potential in the palliative management of mild to moderate Alzheimer's disease (Heinrich and Teoh 2004; Maelicke et al. 2001). This structure acts as a competitive and reversible inhibitor of the human AChE, as well as an allosterical ligand of nicotinic acetylcholine receptors (nAChR) (Zarotsky et al. 2003; Samochocki et al. 2003). Galanthamine was approved by the Food and Drug Administration in 2001, and its hydrobromide salt has been commercialized under the trade names Reminyl ${ }^{\circledR}$ in Europe and Razadine ${ }^{\circledR}$ in USA (Torras-Claveria et al. 2017). This compound was isolated for the first time from the species Galanthus woronowii in the 1950s, and it is currently obtained from Amaryllidaceae species such as Galanthus nivalis, Leucojum aestivum, Lycoris radiata, and different species of Narcissus (TorrasClaveria et al. 2017).

Hippeastrum Herb. is a large genus of the Amaryllidaceae family since it comprises approximately 60 species, which occurs mainly in South America (Meerow and Snijman 1998). Our research group in Porto Alegre (Brazil), through many international collaborations, has been studying Amaryllidaceae plants since 1995, remarkably focusing on Hippeastrum genus. As examples, some articles related with the chemical aspects of H. aulicum Herb., H. breviflorum Herb., H. calyptratum (Ker Gawl.) Herb., H. glaucescens (Mart. Ex Schult. \& Schult. f.) Herb., H. morelianum Lem., H. papilio (Ravenna) Van Scheepen, H. psittacinum (Ker Gawl.) Herb., H. reticulatum Herb., H. santacatarina (Traub) Dutilh, and H. vittatum (L'Hér.) Herb. have been published in the last two decades (Hofmann Jr. et al. 2003; Silva et al. 2006; Pagliosa et al. 2010; de Andrade et al. 2011, 2012a, 2014; Giordani et al. 2011; Sebben et al. 2015; Tallini et al. 2017). Moreover, some contributions in the field of biological activities of AA have also been carried out, such as the anti-inflammatory potential of montanine (3), which brings us a patent licensing (US2016024074) (de Oliveira et al. 2015; Farinon et al. 2017). In 2012, a brief overview of the phytochemical and biological studies in Hippeastrum genus has been reported (de Andrade et al. 2012a). Herein, a review update between 2012 and 2021 is presented.

\section{Search Strategy}

Electronic searches were conducted on Scopus and PubMed database from January 2012 up to March 2021. The search items included Hippeastrum and the name of specific 
Amaryllidaceae alkaloids found in this genus. This review was conducted to analyze the recent literature and to present the chemical and biological advances of this genus in the last years.

\section{Discussion}

\section{Structural Diversity}

In this review, seventeen articles were found to contain the alkaloid profile of twenty-three Hippeastrum extracts (Table S1) published between 2012 and 2021 (de Andrade et al. 2014; Carvalho et al. 2015; Cortes et al. 2015a, b; Sebben et al. 2015; Guo et al. 2016; Ortiz et al. 2016; Bessa et al. 2017; Tallini et al. 2017; Shammari et al. 2019; Gasca et al. 2020; Hoang et al. 2020; Lianza et al. 2020; Feu et al. 2021; Paiva et al. 2021; Shammari et al. 2021; Souza et al. 2021). Twelve species were collected in Brazil, two in Colombia, one in Argentina, one in Vietnam, and all the Hippeastrum cultivars were from the Czech Republic (Table S2). The alkaloid profile of all these samples is summarized in the Supplementary Material (Table S1 and Fig. S1-S9).

Between 2012 and 2021, around 90 Amaryllidaceae alkaloids were identified in Hippeastrum extracts by GC-MS, except in Paiva and co-workers (2021), where LC-MS was used (Table S1). In this review, most part of the alkaloids identified in Hippeastrum belongs to lycorine- (25.8\%), followed by haemanthamine- (15.1\%), homolycorine- $(15.1 \%)$, and galanthamine-type $(9.7 \%)$ (Table S1). However, the skeleton-type narciclasine-, pretazettine-, montanine-, crinine-, galanthindole-, galasine-, and ismine-type, in addition to miscellaneous skeleton, were also detected (Fig. 1).

Concerning the chemodiversity of AA in these species, the alkaloids present in $H$. reticulatum were evaluated in two different regions, i.e., in Thua Thien Hue (Vietnam) (Hoang et al. 2020) and in Espírito Santo (Brazil) (Tallini et al. 2017). Comparing the AA profiles from these two populations, it was observed that they were substantially different (Table S1). The species $H$. puniceum (Lam.) Voss., collected in Santander (Colombia) (Cortes et al. 2015b) and Espírito Santo (Brazil) (Feu et al. 2021), also showed distinct diversity in their alkaloidal contents. These variations may highlight the importance of the edaphoclimatic conditions potentially involved in this heterogeneous chemical profile, as well as the physiological functions of these alkaloids in their plant source.

\section{Lycorine Type}

Lycorine-type skeleton displays a pyrrolo[de]phenanthridine structure and it is originated from an ortho-para' phenolic

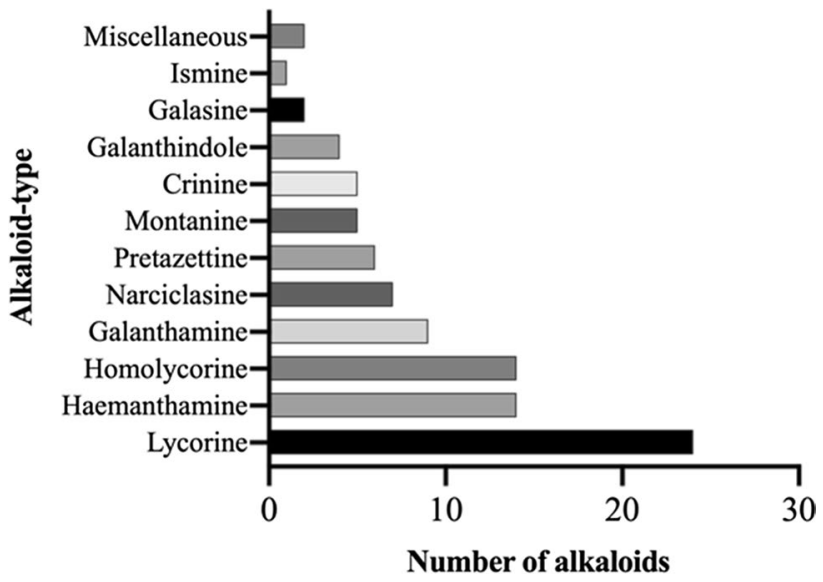

Fig. 1 Graphic representation of the number of alkaloids reported in Hippeastrum genus (2012-2021) distributed by the main chemical scaffolds of Amaryllidaceae alkaloids

oxidative coupling of the precursor 4'-O-methylnorbelladine (1) (Berkov et al. 2020). This is the most diverse group of AA, which provides approximately 119 structures (Berkov et al. 2020). Between 2012 and 2021 (Table S1), 24 structures belonging to this series were reported in Hippeastrum species. These compounds are reported in Fig. S1 for comparison of their structural similarities. Five structures have shown the typical $\mathrm{C}$ ring double bonds at $\mathrm{C} 3$ and $\mathrm{C} 4$, as in lycorine (7), even though nine alkaloids had no $s p^{2}$ carbon at the ring $\mathrm{C}$. Most of the chemical structures displayed substituent at $\mathrm{C} 1$ and/or $\mathrm{C} 2$ as a typical substitution pattern.

According to Table S1, all the Hippeastrum extracts presented lycorine-type alkaloids, except $H$. papilio and H. puniceum, collected in Rio Grande do Sul (Brazil) and Espírito Santo (Brazil), respectively, while the species H. elegans (Spreng.) H.E. Moore evaluated by GC-MS showed the highest diversity of lycorine-type structures in this review. Two new lycorine-type alkaloids named isoreticulinine and reticulinine were described in Hippeastrum extracts in the last years (Tallini et al. 2017).

\section{Haemanthamine Type}

Haemanthamine-type alkaloids are derived from 5,10b-ethanophenanthridine skeleton after a para-para' oxidative phenolic coupling of 4'-O-methylnorbelladine (1), and 76 structures from this group have been reported in Amaryllidaceae family, including the alkaloid known as haemanthamine (9) (Bastida et al. 2006; Berkov et al. 2020). Fourteen alkaloids belonging to this skeleton were identified in Hippeastrum extracts between 2012 and 2021 (Table S1 and Fig. S2). These structures showed substituents at C3, of which the most part is a methoxyl group. Hydroxyl and hydroxybutanoyl groups were also described. Most of the 
haemanthamine-type alkaloids presented a hydroxyl substituent at $\mathrm{C} 11$ being 11-oxohaemanthamine the only exception, showing a ketone carbonyl group.

The 5,10b-ethanophenanthridine skeleton of alkaloids belonging to haemanthamine- and crinine-type usually is confirmed by nuclear magnetic resonance (NMR) and circular dichroism (CD) (León et al. 2021). Among the Hippeastrum studies covered in this review, some alkaloids from the haemanthamine group were only identified by GC-MS, which lead to their assignment as isomers, such as occurs with vittatine shown in Table S1 (Ortiz et al. 2016; Shammari et al. 2019; Lianza et al. 2020; Souza et al. 2021).

The species H. aulicum reported by Bessa et al. (2017) shows the greatest structural diversity in haemanthamine-type alkaloids among the extracts reported in Table S1. Otherwise, haemanthamine-type representatives were not found in the extracts from $H$. breviflorum, $H$. elegans evaluated by LC-MS, both species of $H$. puniceum, $H$. reticulatum collected in Vietnam, and in the Pretty Nymph cultivar. Five new haemanthamine-type alkaloids were described in Hippeastrum extracts between 2012 and 2021, which are haemanthamine- $N$-oxide, 3-O-demethyl-3-O-(3'-hydroxybutanoyl)-haemanthamine, $6 \alpha$-hydroxymaritidine, $6 \beta$-hydroxymaritidine, and 11-oxohaemanthamine (de Andrade et al. 2014; Guo et al. 2016; Bessa et al. 2017; Tallini et al. 2017).

\section{Homolycorine Type}

Homolycorine-type skeleton is originated from an orthopara' phenol oxidative coupling via conversion of norpluviine to lycorenine, bringing up to 80 structures of AA (Bastida et al. 2006; Berkov et al. 2020). Fourteen molecules from this series were reported in the present review, and most of them exhibited the typical double bond between $\mathrm{C} 3$ and $\mathrm{C} 4$, such as occurs in the alkaloid homolycorine (8) (Table S1 and Fig. S3). The absolute configuration of the compound hippapiline isomer was not informed in literature (Souza et al. 2021), and then it was not included in Fig. S3.

According to Table S1, H. aulicum presented the highest structural diversity of homolycorine-type alkaloids while in $H$. breviflorum and H. elegans (analyzed by LC-MS), as well as in $H$. puniceum and $H$. reticulatum, collected in different places, homolycorine-type alkaloids have not been identified (Tables S1 and S2). Considering studies between 2012 and 2021, four new homolycorine-type alkaloids were reported in Hippeastrum genus, which were named hippapiline, $2 \alpha, 10 \mathrm{~b} \alpha$-dihydro-9-O-demethylhomolycorine, 7-hydroxyclivonine, and 7-methoxy- $O$-methyllycorenine (de Andrade et al. 2014; Carvalho et al. 2015; Guo et al. 2016; Ortiz et al. 2016).

\section{Galanthamine Type}

Galanthamine-type skeleton has a dibenzofuran nucleus that derives from a para-ortho' phenolic oxidative coupling of 4'-O-methylnorbelladine (1), and approximately 47 structures from this group have been found in Amaryllidaceae family (Bastida et al. 2006; Berkov et al. 2020). Nine alkaloids from galanthamine-type were reported in Hippeastrum extracts between 2012 and 2021 (Table S1). According to Fig. S4, it is possible to observe two structural subtypes in these extracts, with and without a double bond at $\mathrm{C} 4-\mathrm{C} 4 \mathrm{a}$, and the most part of these structures presented a hydroxyl group at $\mathrm{C} 3$, except narwedine and 3-O-acetyllycoramine.

Among the samples summarized in Table S1, H. elegans evaluated by GC-MS shows the highest diversity in galanthamine-type alkaloids, followed by $H$. goianum (Ravenna) Meerow, both collected in Brazil (Lianza et al. 2020; Souza et al. 2021). A high content of galanthamine (2) was reported in a cultivated $H$. papilio, which is now under a patent number EP2999480B1 (Berkov et al. 2013). The authors informed that the invention provides a composition of an extract from $H$. papillio and its components, which include galanthamine $(88.4 \%)$, narwedine $(1.3 \%)$, haemanthamine (9.6\%), and other alkaloids (0.7\%) (Berkov et al. 2013). Regarding the importance of galanthamine as a marketed drug, the occurrence of nine galanthamine-type alkaloids in Hippeastrum extracts described in Table $\mathrm{S} 1$ highlight this genus as an important natural source of these structures.

\section{Narciclasine Type}

Narciclasine-type includes the alkaloids derived from phenanthridine and phenanthridone/isocarbostiryl skeleton, originated from a para-para phenolic oxidative coupling of 4'-O-methylnorbelladine (1), and comprising so far around 33 structures in Amaryllidaceae family (Bastida et al. 2006; Berkov et al. 2020). According to literature, six alkaloids from this group were identified in Hippeastrum extracts between 2012 and 2021 (Table S1 and Fig. S5), including structures with a glucosyl substituent at $\mathrm{C} 4$, as well as compounds without the usual double bond at $\mathrm{C} 1-\mathrm{C} 2$.

Among the species summarized in Table S1, H. reticulatum from Vietnam shows the greatest diversity in narciclasine-type alkaloids, while no alkaloid from this group was identified in the same species from Brazil. Moreover, narciclasine-type alkaloids were not identified in Hippeastrum cultivars, except cv. Ferrari, where it was reported the presence of trisphaeridine. 


\section{Pretazettine Type}

Pretazettine-type, also known as tazettine-type, is derived from the 2-benzopyrano[3,4-c] indole skeleton, originated from a para-para' phenolic oxidative coupling, and totalized 32 structures in Amaryllidaceae family so far (Bastida et al. 2006; Berkov et al. 2020). Seven structures belonging to this type were identified in Hippeastrum extracts between 2012 and 2021 (Table S1 and Fig. S6), including tazzetine and/or 6-deoxytazettine, which are in fact artifact from pretazettine (10) isolation (de Andrade et al. 2012b). Paiva et al. (2021) proposed the presence of macronine or its isomer epimacronine in $H$. elegans by LC-MS; however, no alkaloid from this group was identified in $H$. elegans by GC-MS (Souza et al. 2021). Among the extracts described in Table S1, it is possible to observe that the species H. barbatum Herb. presented the highest diversity in pretazettine-type alkaloids, although the structure of 6-methoxypretazettine isomer has not been informed by the authors (Cortes et al. 2015a).

\section{Montanine Type}

Montanine-type is derived from 5,11-methanomorphanthridine skeleton and it is originated from a para-para' phenolic oxidative coupling, and fourteen structures from this group were reported in Amaryllidaceae family up to now (Bastida et al. 2006; Berkov et al. 2020). Five alkaloids belonging to this skeleton were described in Hippeastrum extracts between 2012 and 2021 (Table S1 and Fig. S7). All these structures show an $\alpha$-configuration of the 5,11-methanobridge and the hydrogen at $\mathrm{C} 4 \mathrm{a}$ at the $\beta$-position, as in montanine (3). In the present review, the species H. elegans evaluated by Souza et al. (2021) showed the highest diversity in montanine-type structures.

\section{Crinine Type}

Crinine-type skeleton is derived from 5,10b-ethanophenanthridine skeleton and it is originated from a para-para' phenolic oxidative coupling of the common precursor, showing approximately 85 structures in Amaryllidaceae family to date, including the alkaloid named crinine (4) (Bastida et al. 2006; Berkov et al. 2020). Five alkaloids from this series were identified in Hippeastrum extracts between 2012 and 2021 (Table S1 and Fig. S8). Two of them present a methylenedioxy ring at $\mathrm{C} 8 / \mathrm{C} 9$ and one of these structures shows a substituent at C10. Paiva et al. (2021) and Souza et al. (2021) cataloged undulatine diol as a haemanthamine-type structure, but they did not inform its absolute configuration. According to Berkov et al. (2020), the compound undulatine is a crinine-type alkaloid, then undulatine diol was classified into this group in this review (Table S1). Two new crininetype compounds, aulicine and 3-O-methylepimacowine, were reported in Hippeastrum extracts in the last years, which were obtained from the species $H$. aulicum and $H$. calyptratum, respectively (de Andrade et al. 2014).

\section{Other Types}

Galanthindole-type alkaloids are derived from homolycorine-type, totalizing 14 structures in Amaryllidaceae family, including the alkaloid known as galanthindole (5) (Berkov et al. 2020). According to Table S1, four alkaloids from this type were identified in Hippeastrum extracts between 2012 and 2021, two of them reported for the first time in literature: papiline and 9-O-demethyllycosinine $\mathrm{B}$, obtained from $H$. papilio and $H$. breviflorum, respectively (Guo et al. 2016; Sebben et al. 2015). Galasine-type is a small alkaloid group from Amaryllidaceae family, containing only five structures, including the compound galasine (6) (Berkov et al. 2020), and one of them was identified in H. goianum: 7-demethoxy-9-O-methylhostasine (Lianza et al. 2020). The compound 7-demethoxy-9-O-methylhostasine isomer was described in $H$. elegans by GC-MS although the absolute configuration is missing (Souza et al. 2021).

The alkaloids from ismine-type also present few representatives showing just five compounds in Amaryllidaceae family (Berkov et al. 2020). The alkaloid ismine (11) was reported in seven Hippeastrum extracts in the last years (Table S1). The miscellaneous group presents 51 structures in Amaryllidaceae family (Berkov et al. 2020) and two of them, apogalanthamine and $N$-methyltyramine, were identified in $H$. papilio and $H$. reticulatum, respectively (Guo et al. 2016; Hoang et al. 2020). The galanthindole-, galasine-, ismine-, and miscellaneous-type structures identified in Hippeastrum between 2012 and 2021 are illustrated in Fig. S9.

\section{Biological Potential}

Despite the abundant literature available regarding the biological potential of AA, it is important to discuss the new possible targets for the bioactive natural products described in the literature during the period covered in this review. The biological potential of the alkaloids summarized in Table S1 was explored in published literature (Berkov et al. 2020; Cimmino et al. 2017; de Andrade et al. 2012a; Ding et al. 2017; He et al. 2015; Jin and Yao 2019; Masi et al. 2020). Therefore, 30 biological approaches were distributed among 11 alkaloid-type (Fig. 2). These data enabled us to reinforce to Hippeastrum genus the well-recognized potential of AA as cytotoxic, acetylcholinesterase inhibitor, and antiprotozoal scaffolds, mainly regarding the moieties narciclasine-, galanthamine-, and lycorine-types, respectively. In terms of biological evaluations, the cytotoxic activity was the most reported target of AA in the covered period of this review. 


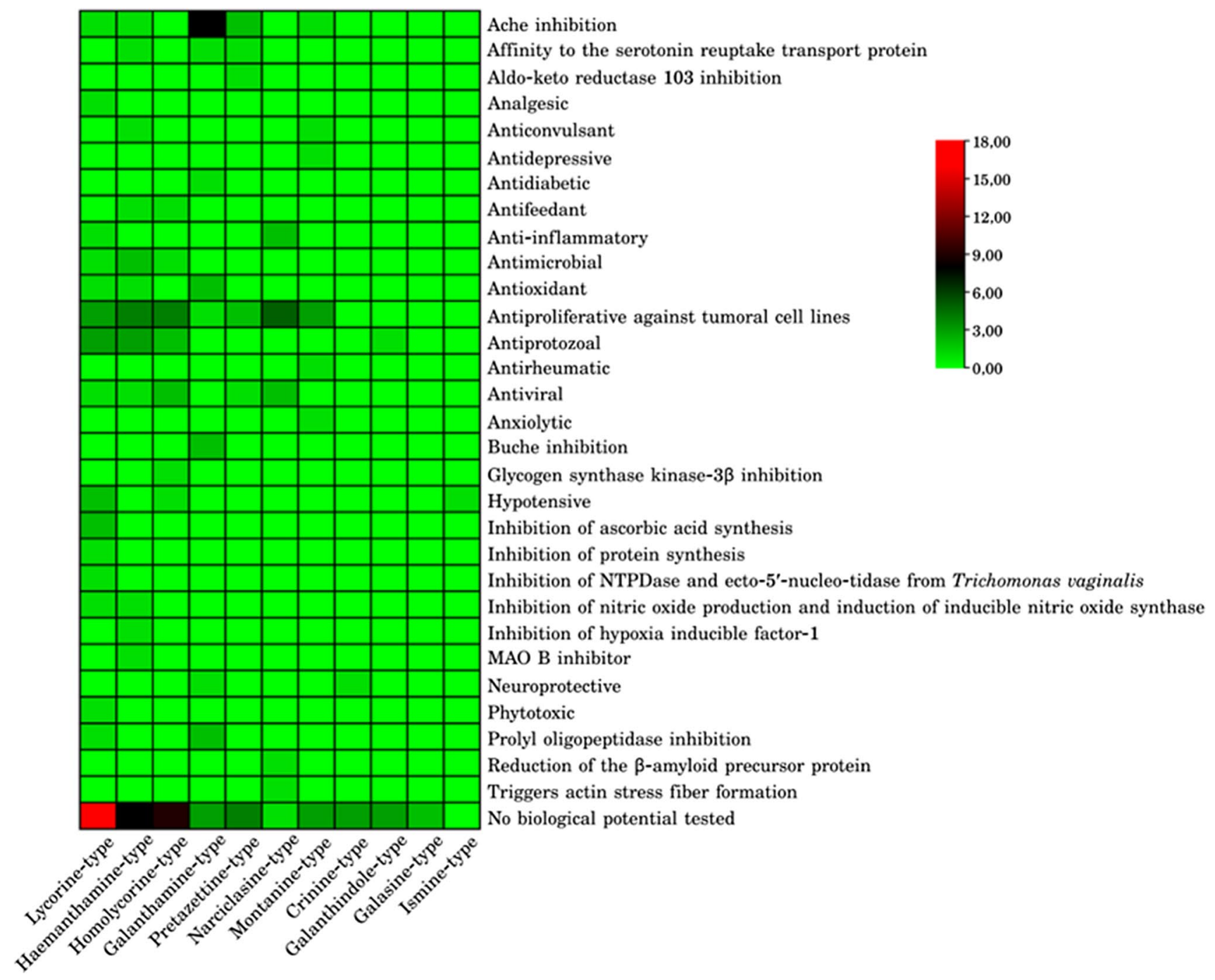

Fig. 2 Heatmap with the correlation among the biological potential previously reported to each alkaloid covered by this review. The 93 alkaloids were grouped in 11 main types according to Table S1. The biological activity data were obtained in several recent reviews

Although lycorine-type was the main skeleton determined in Hippeastrum herein, slightly more than a half (16 alkaloids, $57 \%$ of total) were evaluated biologically.

\section{Biological Activities of New Alkaloids}

Sixteen alkaloids were characterized for the first time from Hippeastrum extracts between 2012 and 2021, but only part of them was evaluated biologically. Computational experiments suggest that isoreticulinine, a new lycorine-type alkaloid obtained from Brazilian $H$. reticulatum, has a great potential as cholinesterase inhibitor (Tallini et al. 2017). Otherwise, the epimer mixture of $6 \alpha$-hydroxymaritidine and $6 \beta$-hydroxymaritidine, assigned for the first time in the same species (H. reticulatum), exhibited only a weak AChE
(Berkov et al. 2020; Cimmino et al. 2017; de Andrade et al. 2012a; Ding et al. 2017; He et al. 2015; Jin and Yao 2019; Masi et al. 2020) and complemented with a search in PubChem database

and no BuChE inhibitory activity (Tallini et al. 2017). In vitro assays showed that the homolycorine-type derivative 7-hydroxyclivonine obtained from $H$. argentinum (Pax) Hunz. collected in Argentina has a weak inhibitory activity against BuChE (Ortiz et al. 2016). In silico approaches also indicated similar binding interactions between 7-hydroxyclivonine and galanthamine (2) into the BuChE pocket (Ortiz et al. 2016).

The mentioned epimer mixture of $6 \alpha$-hydroxymaritidine and $6 \beta$-hydroxymaritidine was also evaluated against four protozoal strains showing $\mathrm{IC}_{50}$ values of $30.68 \mu \mathrm{g} / \mathrm{ml}$ against Trypanosoma brucei rhodesiense, $66.11 \mu \mathrm{g} / \mathrm{ml}$ against Trypanosoma cruzi, $>100 \mu \mathrm{g} / \mathrm{ml}$ against Leishmania donovani, and $32.86 \mu \mathrm{g} / \mathrm{ml}$ against Plasmodium falciparum, as well as 
low cytotoxicity against $\mathrm{L} 6$ cells, with $\mathrm{IC}_{50}$ values higher than $100 \mu \mathrm{g} / \mathrm{ml}$ (Tallini et al. 2017).

Carvalho et al. (2015) evaluated the cytotoxic activity of $2 \alpha, 10 \mathrm{~b} \alpha$-dihydro-9- $O$-demethylhomolycorine, isolated from H. solandriflorum (Lindl.) Herb. collected in Brazil, against human cancer cell lines, and obtained $\mathrm{IC}_{50}$ values of $11.69 \mu \mathrm{M}$ against HCT-116 (colon adenocarcinoma), higher than $50 \mu \mathrm{M}$ against HL-60 (leukemia), $15.11 \mu \mathrm{M}$ against OVCAR-8 (ovarian carcinoma), and $16.31 \mu \mathrm{M}$ against SF-295 (glioblastoma).

\section{Anticancer Properties}

The number of reports considering Amaryllidaceae family as an important source of anticancer drugs has increased in the last years (Nair and Van Staden, 2021). The alkaloid lycorine (7) presented large occurrence between the Hippeastrum extracts, as informed in Table S1, being reported in about $74 \%$ of them. This structure is found in numerous Amaryllidaceae species and displays antitumoral properties against several cancer cell lines through different mechanisms (Bastida et al. 2006). Some authors suggest that lycorine induces mitochondria-dependent apoptosis through rho-associated protein kinase activation in liver cancer cells (HepG2) (Liu et al. 2019). This alkaloid also seems to induce apoptosis in pancreatic cancer cells (PANC-1) through ROS generation to modulate the PI3K/Akt/mTOR signaling pathway (Liu et al. 2016). This compound inhibited the growth of lung cancer cells via modulating miR-186/CDK1 axis ( $\mathrm{Li}$ et al. 2019), the growth of glioblastoma multiforme tumors by means of epidermal growth factor receptor suppression (Shen et al. 2018), and the growth and metastasis of breast cancer as a result of the blockage of the signal transducer and activator of transcription 3 (STAT3) signaling pathway (Wang et al. 2017). In the last years, lycorine has been cataloged as a strong apoptosis inducer, and many studies have been reporting its action mechanism in different cancer cells lines, turning it an attracting scaffold in the development of new drugs for the cancer clinical therapy (Roy et al. 2018).

About $40 \%$ of the alkaloids identified in Hippeastrum extracts showed the presence of the alkaloid haemanthamine in their profile (Table S1). This structure has been identified on many occasions in Amaryllidaceae plants and has received considerable attention in the last years due to its cytotoxic properties (Doskocil et al. 2015; Cahlíková et al. 2021). This alkaloid can trigger apoptosis in many cell lines (Nair and Van Staden, 2019). Some authors suggest that haemanthamine (9) inhibited specifically ribosome biogenesis, triggering nucleolar stress response and leading to p53 stabilization in cancer cells (Pellegrino et al. 2018). This compound seems to be able to inhibit cell proliferation, to increase apoptosis accompanied by caspases activation, to decrease mitochondrial membrane potential, and to arrest the cell cycle in p53-null $\mathrm{T}$ cell leukemia Jurkat cells within $24 \mathrm{~h}$ of treatment (Havelek et al. 2014).

Among the homolycorine-type structures reported in Table S1, the alkaloid homolycorine (8) presented large occurrence between the Hippeastrum species, while the metabolite hippeastrine was the most frequently found among the Hippeastrum cultivars. According to literature, hippeastrine has been shown to be one of the most potent alkaloids in the homolycorine-type series with activities against most of 26 cell lines to which it has been exposed (Nair and Van Staden, 2021). This molecule exhibited a good dose-dependent inhibitory effect against topoisomerase I with $\mathrm{IC}_{50}$ values at $7.25 \pm 0.20 \mu \mathrm{g} / \mathrm{ml}$, as compared to the positive control (camptothecin) at $6.72 \pm 0.23 \mu \mathrm{g} / \mathrm{ml}$ (Chen et al. 2016).

A few numbers of narciclasine-type structures have been described among the Hippeastrum extracts reported in Table S1. Nevertheless, this alkaloid group has been gaining attention of the scientists due its anticancer properties, which were evaluated in various phases of clinical trials (Kornienko and Evidente 2008). The compound narciclasine (12) presented potent antimitotic effect against the highly malignant mouse sarcoma cells (Scarcoma 180) passaged in the ascites form (Ceriotti 1967; Kornienko and Evidente 2008). This alkaloid inhibited the step of peptide bond formation during elongation by binding to the 60S tRNA A-site (Loubresse et al. 2014; Fürst 2016). According to Cao et al. (2018), narciclasine inhibited proliferation of triple-negative breast cancer cells by regulating AMPK-ULK1 signaling and thereby stimulating autophagy-dependent apoptosis.

\section{Perspectives and Future Directions}

The maintenance of chemical and biological approaches on AA may lead to discover new structures along with their actual potential as bioactive compounds. Furthermore, many well-known alkaloids still deserve better evaluations around their real potential in different biological targets. Unfortunately, the scarce number of isolated substances in preparative scale, as well as the use of hyphenated chromatography techniques for dereplication and identification of constituents in alkaloidal extracts have impaired the biological assays of pure alkaloids. Otherwise, the "Omics" era has provided a great improvement in analytical approaches such as automatized sample fractionations and biological protocols miniaturized. These enhancements can magnify the range of pharmacological assessment in a near future. Biosynthetic studies to determine alternative pathways to obtain alkaloids in a scale-up approaches, along with their production through biotechnology, could be a valuable strategy to the future in the AA pharmacology. Finally, the use of metabolic engineering in Amaryllidaceae species together 
with a fractionation and biological assay can be a promising way to the next years as a new perspective of scientific and industrial exploitation of Hippeastrum genus.

\section{Conclusions}

Overall, studies on the Hippeastrum genus, in the last nine years, reinforce the importance of the chemical diversity along with a deep biological evaluation on the AA. This genus could be classified as a hotspot of new chemical entities, and several aspects remain to be investigated. Various extracts of species included in this review can be considered a real source of a preferential alkaloid scaffolds, but also as a source of bioactive structures for the development of new drug candidates, including agents for cancer therapy.

Supplementary Information The online version contains supplementary material available at https://doi.org/10.1007/s43450-021-00211-z.

Acknowledgements LRT is thankful to CAPES (Coordenação de Pessoal de Nível Superior, Brasil) for a doctoral (Processo 13553135) and postdoctoral fellowship. JASZ acknowledges CNPQ for the research fellowship.

Author Contribution LRT, RBG, JPA, and JASZ have done the electronic data searches and wrote the manuscript. JB and JASZ supervised the work. The authors have read and agreed to the manuscript.

Funding Financial support was provided by Programa Iberoamericano de Ciencia y Tecnología para el Desarrollo, CYTED (BIFRENES 416RT0511) and Conselho Nacional de Desenvolvimento Científico e Tecnológico (CNPq), National Institute of Science and TechnologyINCT BioNat, grant \# 465637/2014-0, Brazil.

\section{References}

Barton DHR, Cohen T (1956) Some biogenic aspects of phenol oxidation. In Festschrift Arthur Stoll; Birkhauser AG (ed) Birkhauser: Basel, Switzerland 117-143.

Bastida J, Lavilla R, Viladomat F (2006) Chemical and biological aspects of Narcissus alkaloids. In: Cordell GA (ed), The Alkaloids: Chemistry and Physiology. 63, Elsevier, Amsterdam 87-179

Battersby AR, Fales HM, Wildman WC (1961) Biosynthesis in the Amaryllidaceae. Tyrosine and norbelladine as precursors of haemanthamine. J Am Chem Soc 83:4098-4099

Berkov S, Bastida J, Codina C, de Andrade JP, Berbee RLM (2013) Extract of Hippeastrum papilio rich in galanthamine. Patent number: EP2999480B 1

Berkov S, Osorio E, Viladomat F, Bastida J (2020) Chemodiversity, chemotaxonomy and chemoecology of AA. In: Knölker H-J (ed), The Alkaloids: Chemistry and Biology. 83, Elsevier, Amsterdam 113-185. https://doi.org/10.1016/bs.alkal.2019.10. 002

Bessa CDPB, de Andrade JP, Oliveira RS, Domingos E, Santos H, Romão W, Bastida J, Borges W (2017) Identification of alkaloids from Hippeastrum aulicum (Ker Gawl.) Herb. (Amaryllidaceae) using CGC-MS and ambient ionization mass spectrometry (PS-MS and LS-MS). J Braz Chem Soc 28:819-830. https://doi.org/10.21577/0103-5053.20160234

Cahlíková L, Vrabec R, Pidaný F, Perinová R, Maafi N, Mamun AA, Ritomská A, Wijaya V, Blunden G (2021) Recent progress on biological activity of Amaryllidaceae and further isoquinoline alkaloids in vonnection with Alzheimer's Disease. Molecules 26:5240. https://doi.org/10.3390/molecules26175240

Cao C, Huang W, Zhang N, Wu F, Xu T, Pan X, Peng C, Han B (2018) Narciclasine induces autophagy-dependent apoptosis in triplenegative breast cancer cells by regulating the AMPK-ULK1 axis. Cell Proliferat 51:e12518. https://doi.org/10.1111/cpr.12518

Carvalho KB, Silva AB, Torres MCM, Pinto FCL, Guimarães LA, Rocha DD, Silveira ER, Costa-Lotufo LV, Braz-Filho R, Pessoa ODL (2015) Cytotoxic alkaloids from Hippeastrum solandriflorum Lindl. J Brazil Chem Soc 26:1976-1980. https://doi.org/10. 5935/0103-5053.20150176

Ceriotti G (1967) Narciclasine: an antimitotic substance from Narcissus bulbs. Nature 213:595-596. https://doi.org/10.1038/213595a0

Chen G-1, Tian Y-q, Wu J-1, Li N, Guo M-q (2016) Antiproliferative activities of Amaryllidaceae alkaloids from Lycoris radiata targeting DNA topoisomerase I. Sci Rep 6:38284. https://doi.org/ $10.1038 /$ srep38284

Chinsembu KC (2020) Coronaviruses and nature's pharmacy for the relief of coronavirus disease 2019. Rev Bras Farmacogn 30:603621. https://doi.org/10.1007/s43450-020-00104-7

Cimmino A, Masi M, Evidente M, Superchi S, Evidente A (2017) AA: Absolute configuration and biological activity. Chirality 29:486-499. https://doi.org/10.1002/chir.22719

Cordell GA, Quinn-Beattie ML, Farnsworth NR (2001) The potential of alkaloids in drug discovery. Phytother Res 15:183-205. https:// doi.org/10.1002/ptr.890

Cortes N, Posada-Duque RA, Alvarez R, Alzate F, Berkov S, Cardona-Gómez GP, Osorio E (2015a) Neuroprotective activity and acetylcholinesterase inhibition of five Amaryllidaceae species: a comparative study. Life Sci 122:42-50. https://doi.org/10.1016/j. lfs.2014.12.011

Cortes N, Alvarez R, Osorio EH, Alzate F, Berkov S, Osorio E (2015b) Alkaloid metabolite profiles by GC/MS and acetylcholinesterase inhibitory activities with binding-mode predictions of five Amaryllidaceae plants. J Pharmaceut Biomed 102:222-228. https:// doi.org/10.1016/j.jpba.2014.09.022

de Andrade JP, Berkov S, Viladomat F, Codina C, Zuanazzi JAS, Bastida J (2011) Alkaloids from Hippeastrum papilio. Molecules 15:7097-7104. https://doi.org/10.3390/molecules16087097

de Andrade JP, Pigni NB, Torras-Claveria L, Guo Y, Berkov S, ReyesChilpa R, Amrani AE, Zuanazzi JAS, Codina C, Viladomat F, Bastida J (2012a) Alkaloids from the Hippeastrum genus: chemistry and biological activity. Rev Latinoam Quim 40:83-98

de Andrade JP, Pigni NB, Torras-Claveria L, Berkov S, Codina C, Viladomat F, Bastida J (2012b) Bioactive alkaloid extracts from Narcissus broussonetii: mass spectral studies. J Pharmaceut Biomed 70:13-25. https://doi.org/10.1016/j.jpba.2012.05.009

de Andrade JP, Guo Y, Font-Bardia M, Calvet T, Dutilh J, Viladomat F, Codina C, Nair JJ, Zuanazzi JAS, Bastida J (2014) Crinine-type alkaloids from Hippeastrum aulicum and $H$. calyptratum. Phytochemistry 103:188-195. https://doi.org/10.1016/j.phytochem. 2014.03.007

de Oliveira PG, Pedrazza GPR, Farinon M, Xavier RM, Zuanazzi JAS, Spies F (2015) Method for extracting the alkaloid fraction of Rhodophiala bifida (Herb.) Traub. and uses thereof. Patent number: US2016024074

Ding Y, Qu D, Zhang KM, Cang XX, Kou ZN, Xiao W, Zhu JB (2017) Phytochemical and biological investigations of AA: a 
review. J Asian Nat Prod Res 19:53-100. https://doi.org/10. 1080/10286020.2016.1198332

Doskocil I, Hoštálková A, Šafratová M, Benešová N, Havlík J, Havelek R, Kuneš J, Královec K, Chlebek J, Cahlíková L (2015) Cytotoxic activities of Amaryllidaceae alkaloids against gastrointestinal cancer cells. Phytochem Lett 13:394-398. https:// doi.org/10.1016/j.phytol.2015.08.004

Farinon M, Clarimundo VS, Pedrazza GPR, Gulko PS, Zuanazzi JASZ, Xavier RM, Oliveira PG (2017) Disease modifying antirheymatic activity of the alkaloid montanine on experimental arthritis and fibroblast-like synoviocytes. Eur J Pharmacol 799:180-187. https://doi.org/10.1016/j.ejphar.2017.02.013

Feu AE, de Andrade JP, Ayala AP, Almeida LC, Costa-Lotufo LV, Bastida J, Ellena J, Borges WS (2021) Glycosylatednarciclasine alkaloid in Hippeastrum puniceum (Lam.) Kuntze. S Afri J Bot 136:30-34. https://doi.org/10.1016/j.sajb.2020.09.006

Fürst R (2016) Narciclasine - an Amaryllidaceae alkaloid with potent antitumor and anti-inflammatory properties. Plant Med 82:1389-1394. https://doi.org/10.1055/s-0042-115034

Gasca CA, Moreira NCS, Almeida FC, Gomes JVD, Castillo WO, Fagg CW, Magalhães PO, Fonsceca-Bazzo YM, Sakamoto-Hojo W, Medeiros YK, Borges WS, Silveira D (2020) Acetylcholinesterase inhibitory activity, anti-inflammatory, and neuroprotective potential of Hippeastrum psittacinum (ker Gawl.) Herb. (Amaryllidaceae). Food Chem Toxicol 145:11703. https://doi. org/10.1016/j.fct.2020.111703

Giordani RB, de Andrade JP, Verli H, Dutilh JH, Henriques AT, Berkov S, Bastida J, Zuanazzi JAS (2011) Alkaloids from Hippeastrum morelianum Lem. (Amaryllidaceae). Magn Reson Chem 49:668-672. https://doi.org/10.1002/mrc.2794

Guo Y, de Andrade JP, Pigni NB, Torras-Claveria L, Tallini LR, Borges WS, Viladomat F, Nair JJ, Zuanazzi JAS, Bastida J (2016) New alkaloids from Hippeastrum papilio (Ravenna) Van Scheepen. Helv Chim Acta 99:143-147. https://doi.org/ 10.1002/hlca.201500188

Hardy K (2021) Paleomedicine and the evolutionary context of medicinal plant use. Rev Bras Farmacogn 31:1-15. https://doi. org/10.1007/s43450-020-00107-4

Havelek R, Seifrtova M, Kralovec K, Bruckova L, Cahlikova L, Dalecka M, Vavrova J, Rezacova M, Opletal L, Bilkova Z (2014) The effect of Amaryllidaceae alkaloids haemanthamine and haemanthidine on cell cycle progression and apoptosis in p53-negative human leukemic Jurkat cells. Phytomedicine 21:479-490. https://doi.org/10.1016/j.phymed.2013.09.005

He M, Qu C, Gao O, Hu X, Hong X (2015) Biological and pharmacological activities of AA. RSC Adv 5:16562. https://doi.org/ 10.1039/C4RA14666B

Heinrich M, Teoh HL (2004) Galanthamine from snowdrop - the development of a modern drug against Alzheimer's disease from local Caucasian knowledge. J Ethnopharmacol 92:147-162. https://doi.org/10.1016/j.jep.2004.02.012

Hoang THX, Ho DV, Phan KV, Le QV, Raal A, Nguyen HT (2020) Effects of Hippeastrum reticulatum on memory, spatial learning and object recognition in a scopolamine-ibduced animal model of Alzheimer's disease. Pharm Biol 58:1098-1104. https://doi. org/10.1080/13880209.2020.1841810

Hofmann Jr. AE, Sebben C, Sobral MEG, Dutilh J, Henriques AT, Zuanazzi JAS (2003) Alkaloids of Hippeastrum glaucescens. Biochem Syst Ecol 31:1455-1456. https://doi.org/10.1016/ S0305-1978(03)00129-7

Jin Z, Yao G (2019) Amaryllidaceae and Sceletium alkaloids. Nat Prod Rep 36:1462-1488. https://doi.org/10.1039/c3np70005d

Kilgore MB, Kutchan TM (2015) The Amaryllidaceae alkaloids: biosynthesis and methods for enzyme discovery. Phytochem Rev 15:317-337. https://doi.org/10.1007/s11101-015-9451-z
Komolafe K, Komolafe TR, Fatoki TH, Akinmoladun AC, Brai B, Olaleye MT, Akindahunsi AA (2021) Coronavirus disease 2019 and herbal therapy: pertinent issues relating to toxicity and standardization of phytopharmaceuticals. Rev Bras Farmacogn 31:142161. https://doi.org/10.1007/s43450-021-00132-x

Kornienko A, Evidente A (2008) Chemistry, biology and medicinal potential of narciclasine and its congeners. Chem Rev 108:19822014. https://doi.org/10.1021/cr078198u

Léon KA, Inca A, Tallini LR, Osorio EH, Robles J, Bastida J, Oleas NH (2021) Alkaloids of Phaedranassa dubia (Kunth) J.F. Macbr. and Phaedranassa brevifolia Meerow (Amaryllidaceae) from Ecuador and its cholinesterase-inhibitory activity. S Afri J Bot 136:91-99. https://doi.org/10.1016/j.sajb.2020.09.007

Li L, Zhang Z, Yang Q, Ning M (2019) Lycorine inhibited the cell growth of non-small cell lung cancer by modulating the miR186/CDK1 axis. Life Sci 231:116528. https://doi.org/10.1016/j. lfs.2019.06.003

Lianza M, Verdan MH, de Andrade JP, Poli F, Almeida LC, CostaLotufo L, Neto AC, Oliveira SCC, Bastida J, Batista ANL, Batista JM Jr, Borges W (2020) Isolation, absolute configuration and cytotoxic activities of alkaloids from Hippeastrum goianum (Ravenna) Meerow (Amaryllidaceae). J Brazil Chem Soc 31:2135-2145. https://doi.org/10.21577/0103-5053.20200116

Liu Q, Hu S, Zhang Y, Zhang G, Liu S (2016) Lycorine induces apoptosis in human pancreatic cancer cell line PANC-1 via ROS-mediated inactivation of PI3K/Akt/mTOR signaling pathway. Int J Clin Exp Med 9:21048-21056

Liu W-Y, Tang Q, Zhang Q, Hu C-P, Huang J-B, Sheng F-F, Liu Y-L, Zhou M, Lai W-J, Zhang L-BR (2019) Lycorine induces mitochondria-dependent apoptosis in hepatoblastoma HepG2 cells through ROCK1 activation. Front Pharmacol 10:651. https://doi. org/10.3389/fphar.2019.00651

Loubresse NG, Prokhorova I, Holtkamp W, Rodnina MV, Yusupova G, Yusupov M (2014) Structural basis for the inhibition of the eukaryotic ribosome. Nature 513:517-522. https://doi.org/10. 1038/nature 13737

Maelicke A, Samachocki M, Jostock R, Fehrenbacher A, Ludwig J, Albuquerque EX, Zerlin M (2001) Allosteric sensitization of nicotine receptors by galanthamine, a new treatment strategy for Alzheimer's disease. Biol Psychiat 49:279-288. https://doi.org/ 10.1016/s0006-3223(00)01109-4

Masi M, Di Lecce R, Cimmino A, Evidente A (2020) Advances in the chemical and biological characterization of AA and natural analogues isolated in the last decade. Molecules 25:5621. https:// doi.org/10.3390/molecules25235621

Nair JJ, Van Staden J (2019) Caspase-inducing effects of lycorine and crinane alkaloids of the Amaryllidaceae. S Afr J Bot 120:33-38. https://doi.org/10.1016/j.sajb.2018.05.016

Nair JJ, Van Staden J (2021) The plant family Amaryllidaceae as a source of cytotoxic homolycorine alkaloid principles. S Afr J Bot 136:157-174. https://doi.org/10.1016/j.sajb.2020.07.013

Pagliosa LB, Monteiro SC, Silva KB, de Andrade JP, Dutilh J, Bastida J, Cammarota M, Zuanazzi JAS (2010) Effect of isoquinoline alkaloids from two Hippeastrum species on in vitro acetylcholinesterase activity. Phytomedicine 17:698-701. https://doi.org/ 10.1016/j.phymed.2009.10.003

Paiva JR, Souza ASQ, Pereira RCA, Ribeiro PRV, Filho EGA, Silva LMA, Zocolo GJ, Brito ES, Alves DR, Morais SMM, Tavares J, Pinto FCL, Andrade GM, Pessoa ODL, Canuto KM (2021) Chemical composition and anticholinesterase activity of cultivated bulbs from Hippeastrum elegans, a potential tropical source of bioactive alkaloids. Phytochem Lett 43:27-34. https://doi.org/10. 1016/j.phytol.2021.03.004

Pellegrino S, Meyer M, Zorbas C, Bouchta AS, Saraf K, Pelly SC, Yusupova G, Evidente A, Mathieu V, Kornienko A, Lafontaine DLJ, Yusupov M (2018) The Amaryllidaceae alkaloid 
haemanthamine binds the eukaryotic ribosome to repress cancer cell growth. Structure 26:416-425. https://doi.org/10.1016/j.str. 2018.01.009

Ortiz JE, Pigni NB, Andujar SA, Roitman G, Suvire FD, Enriz RD, Tapia A, Bastida J, Feresin GE (2016) Alkaloids from Hippeastrum argentinum and their cholinesterase-inhibitory activities: an in vitro and in silico study. J Nat Prod 79:1241-1248. https://doi. org/10.1021/acs.jnatprod.5b00785

Roy M, Liang L, Xiao X, Feng P, Ye M, Liu J (2018) Lycorine: a prospective natural lead for anticancer drug discovery. Biomed Pharmacother 107:615-624. https://doi.org/10.1016/j.biopha. 2018.07.147

Samochocki M, Höffle A, Fehrencacher A, Jostock R, Ludwig J, Christner C, Radina M, Zerlin M, Ullmer C, Pereira EFR, Lübbert H, Albuquerque EX, Maelicke A (2003) Galantamine is an allosterically potentiating ligand of neuronal nicotinic but not of muscarinic acetylcholine receptors. J Pharmacol Exp Ther 305:1024-1036. https://doi.org/10.1124/jpet.102.045773

Sebben C, Giordani RB, de Andrade JP, Berkov S, Osorio JE, Sobral M, Almeida MV, Henriques AT, Bastida J, Zuanazzi JAS (2015) New lycosinine derivative from Hippeastrum breviflorum. Rev Bras Farmacogn 25:353-355. https://doi.org/10.1016/j.bjp.2015. 06.005

Shammari LA, Mamun AA, Koutová D, Majorosová M, Hulcová D, Safratová M, Breiterová K, Mariková J, Havelek R, Cahliková L (2019) Alkaloid profiling of Hippeastrum cultivars by GC-MS, isolation of AA and evaluation of their cytotoxicity. Rec Nat Prod 14:154-159. https://doi.org/10.25135/rnp.147.19.06.1302

Shammari LA, Hulcová D, Maríková J, Kucera T, Safratová M, Nováková L, Schimidt M, Pulkrábková L, Janousek J, Soukup O, Kunes J, Opletal L, Cahlíková L (2021) AA from Hippeastrum X Hybridum CV. Ferrari, and preparation of vittatine derivatives as potential ligands for Alzheimer's disease. S Afri J Bot 136:137-146. https://doi.org/10.1016/j.sajb.2020.06.024

Shen J, Zhang T, Cheng Z, Zhu N, Wang H, Lin L, Wang Z, Yi H (2018) Lycorine inhibits glioblastoma multiforme growth through
EGFR suppression. J Exp Clin Canc Res 37:157. https://doi.org/ 10.1186/s13046-018-0785-4

Silva AFS, de Andrade JP, Bevilaqua LRM, Souza MM, Izquierdo I, Henriques AT, Zuanazzi JAS (2006) Anxiolytic-, antidepressantand anticonvulsant-like effects of the alkaloid montanine isolated from Hippeastrum vittatum. Pharmacol Biochem Be 85:148-154. https://doi.org/10.1016/j.pbb.2006.07.027

Singh A, Desgagné-Penix I (2014) Biosynthesis of the Amaryllidaceae alkaloids. Plant Sci Today 1:114-120. https://doi.org/10.14719/ pst.2014.1.3.41

Souza ASQ, Sousa JAC, Pinto CS, Filho EGA, Pereira RCA, Brito ES, Canuto KM, Leal LKAM (2021) Untargeted GC/MS-based approach for identification of anti-inflammatory alkaloids from Hippeastrum elegans (Amaryllidaceae) using a human neutrophil model. J Pharmaceut Biomed 199:114061. https://doi.org/ 10.1016/j.jpba.2021.114061

Spies P, Grobler JP, Spies JJ (2011) A review of phylogenetic relationships in the genus Clivia. Philos Trans Genet 1:168-207

Tallini LR, Osorio EH, Santos VD, Borges WS, Kaiser M, Viladomat F, Zuanazzi JAS, Bastida J (2017) Hippeastrum reticulatum (Amaryllidaceae): alkaloid profiling, biological activities and molecular docking. Molecules 22:2191. https://doi.org/10.3390/ molecules22122191

Torras-Claveria L, Tallini L, Viladomat F, Bastida J (2017) Research in natural products: Amaryllidaceae ornamental plants as sources of bioactive compounds. In: Recent Advances in Pharmaceutical Sciences VII; Muñoz-Torrero D, Riu M, Feliu C (eds) Research Signpost Trivandrum: Kerala, India 69-82.

Wang J, Xu J, Xing G (2017) Lycorine inhibits the growth and metastasis of breast cancer through the blockage of STAT3 signaling pathway 49(9):771-779. https://doi.org/10.1093/abbs/gmx076

Zarotsky V, Sramek JJ, Cutler NR (2003) Galanthamine hydrobromide: an agent for Alzheimer's disease. Am J Health-Syst Pharm 60:446-452. https://doi.org/10.1093/ajhp/60.5.446 